\title{
A Microbial Community Ecology Perspective on the Gut-Microbiome-Brain Axis
}

\author{
Els van der Goot ${ }^{1,2}$, Francjan J. van Spronsen ${ }^{3}$, Joana Falcão Salles ${ }^{2 \star t}$ and \\ Eddy A. van der Zee ${ }^{1 * t}$
}

${ }^{1}$ Molecular Neurobiology, Groningen Institute for Evolutionary Sciences, University of Groningen, Groningen, Netherlands, ${ }^{2}$ Microbial Ecology Cluster, Groningen Institute for Evolutionary Sciences, University of Groningen, Groningen, Netherlands, ${ }^{3}$ Department of Pediatrics, Beatrix Children's Hospital, University Medical Center Groningen, Groningen, Netherlands

Keywords: microbiome, phenylketonuria, brain, behavior, probiotics

OPEN ACCESS

Edited by:

Isabel Moreno-Indias,

Biomedical Research Institute of Malaga, University of Málaga, Spain

Reviewed by:

Ger Rijkers,

University College

Roosevelt, Netherlands

*Correspondence:

Joana Falcão Salles

j.falcao.salles@rug.n

Eddy A. van der Zee

e.a.van.der.zee@rug.n

${ }^{\dagger}$ These authors have contributed equally to this work and share senior authorship

Specialty section:

This article was submitted to

Translational Endocrinology, a section of the journal

Frontiers in Endocrinology

Received: 02 April 2020

Accepted: 27 July 2020

Published: 02 September 2020

Citation:

van der Goot E, van Spronsen FJ, Falcão Salles J and van der Zee EA

(2020) A Microbial Community

Ecology Perspective on the

Gut-Microbiome-Brain Axis.

Front. Endocrinol. 11:611.

doi: 10.3389/fendo.2020.00611
The gut microbiome is the collection of all microbial cells and associated genetic material present in the digestive tract of a host. Its composition depends on the gut environment and nutrition provided by the host (1). In turn, the microbes help the host by metabolizing complex nutrients, protecting against pathogens and priming their immune system $(1,2)$. In fact, the influence of the gut microbiome on host development goes beyond nutrition and immune response, by also regulating host behavioral and neurological responses $(3,4)$.

Microbiome-associated phenotypes can be seen as means for adaptation and natural selection, presenting an accessible point on which selection could work to tweak host-phenotype in case of changes in environmental conditions (5). From an animal perspective, the microbiome-associated phenotypes gained interest when Bercik et al. showed that fecal matter transplantation could direct strain-specific behavior of the recipient toward strain-specific behavior of the donor (6). Since then, a growing body of evidence has supported the effects of the microbiome on brain and behavior and the concept of a gut-microbiome-brain axis [see for reviews $(3,4)$ ].

Although the microbiome-gut-brain-axis has been implicated in the pathophysiology of various (mental) diseases $(3,4)$, it is often an overlooked aspect in many (metabolic) disorders associated with behavioral deficits and treatments on a dietary basis. Which is remarkable, as diet is one of the main determinants of the gut microbiome and affects the (development) of cognitive (dys)function $(7,8)$. Moreover, beneficial effects of probiotic treatment on cognition have been reported for pathological conditions such as irritable bowel syndrome and coeliac disease (9).

Despite the growing interest in gut microbiome, the ecological aspects associated with these microbial communities are often not considered in the interpretation of the data, although they might contribute to the great variability in host performance often observed after microbiome manipulation, potentially leading to inconclusive interpretation of the data $(10,11)$. For instance, as communities, the gut microbiome is not static, being subjected to large fluctuations that reflect interactions among resident and transient microbial species and the host. From an ecological perspective, these interactions are driven by rules associated with microbial succession, as they reflect changes in community composition in response to processes such as selection and drift (12). Moreover, approaches targeting microbiome manipulation, including the development of probiotics (the "good" bacteria) or prebiotics (food for probiotics), require unraveling the ecological principles controlling microbial invasion, where mechanisms associated with microbial diversity and resource competition can help predicting the outcome of these strategies (11).

Despite the potential of using microbiome-related strategies to improve current treatment and neurological outcome of (metabolic) disorders, we argue that unraveling the ecological 
principles associated with the community dynamics is crucial, and subsequently a prerequisite to ensure the success in microbial-based treatments. To put our opinion in context, we will use the metabolic disorder phenylketonuria (PKU) to illustrate and explain how general concepts of community dynamics and resource availability, eco-evolutionary aspects and microbial invasions, apply in situations where the environment of the gastrointestinal tract is challenged and diet or probiotics are used to prevent neurological problems.

\section{THE GUT MICROBIOME IN THE CONTEXT OF PKU}

PKU is an enzymatic deficiency of the hepatic phenylalanine hydroxylase which results in dramatically increased levels of Phe $(>600 \mu \mathrm{mol} / \mathrm{L})$. It can reach levels that are considered to be toxic for the brain, leading to severe intellectual disability (13-15). The most common treatment is to restrict the intake of natural protein in the diet, thus preventing high Phe levels in the brain, while supplementing with amino acids and essential micronutrients to avoid deficiencies (15-17). When followed early and continuously, this treatment is very effective in keeping Phe levels within an acceptable range (360-600 $\mu \mathrm{mol} / \mathrm{L})$, preventing severe high-Phe associated intellectual disability (15). Nevertheless, in many PKU patients with normal cognitive function Phe levels still influence brain performance (18). Alternatively, it has been shown that inconsistencies in neurocognitive, psychosocial and metabolic consequences of PKU remain, despite treatment (19-22).

It has been shown, that elevated Phe levels are not only present in the blood and brain, but are also manifesting in the gut (23). The microbes in the gut environment are constantly competing for resources, which become available either through host nutrition or the by-products generated by the microbial chemical food webs $(24,25)$. Together, the selective pressure exerted by the available resources and biotic interactions pressure play important roles in determining the microbiome composition in the gut of a given host (12, 26, 27). This means that the microbiome of PKU patients is constantly challenged by situations ranging between two extremes, depending on adherence to treatment; untreated with altered amino acid profiles and high Phe-levels, or low Phe-levels accompanied by a change in resource availability due to the strict dietary requirements. As the microbiome is adaptive in nature, this is likely to result in an altered microbial community. In both situations, alterations are likely to cause a less diverse microbiome, as Phe has been shown to be toxic to certain cell types (neurons), and resource restriction (natural protein) will challenge microbial species that either rely on these resources or are vulnerable to it, making it less likely to establish or to be successful (survival). Results from both PKU mice and patients show that, indeed, the PKU-associated microbiome is often less diverse and more variable between individuals, indicating dominance of a few species within a community (28-31). Moreover, studies that have examined prebiotic supplementation in PKU infant formula or the prebiotic properties of medical foods (glycomacropeptide) showed promising results in maintaining or increasing microbial diversity, indicating that altered resources might influence microbiome diversity in $\mathrm{PKU}(30,32)$.

From a microbial ecology standpoint, the consequences of a less diverse microbiome include the community susceptibility to disturbances. Ecological theories predict that high diversity acts a biotic barrier, contributing to a stable microbiome or promoting microbiome resilience, capable of returning to the original, healthy state, upon disturbance. Thus, a reduction in gut microbial diversity significantly limits the ability of the microbiome to withstand major shifts, potentially leading to alternate, diseased, stable states $(33,34)$.

Another importance consequence of reduction in gut microbiome diversity or shifts in composition in PKU patients is the associated changes in the metabolite profiles of the microbiome, potentially modulating the chemical food web, thus influencing stability, as well as the molecules involved in microbiome-gut-brain signaling and brain functioning (3538). In general, although many functions carried out by the microbiome show functional redundancy, i.e., that multiple populations are capable of carrying out that function, variability in the observed function after microbiome manipulation is greater than the change in gene frequency (10). This means that the interactions within the community strongly impact the functionality of the microbiome. As these functions include production of neurological signaling molecules, a dysfunctional microbiome could lead to behavioral symptoms. In case of dietary treated pathological conditions like PKU, the functionality of the microbiome could therefore impact the neurocognitive, psychosocial and metabolic outcome, despite a highly demanding diet. To optimize the outcome, and thus improving quality of life, a promising alternative would be the development of probiotics that could promote microbial diversity and microbiome functionality. Such approaches have been successfully used in other metabolic diseases (obesity related insulin insensitivity and type 2 diabetes), which are also associated with a dysbiotic gut microbiota and reduced microbial complexity $(39,40)$.

\section{ECO-EVOLUTIONARY ASPECTS ASSOCIATED WITH PROBIOTIC SUPPLEMENTATION}

Probiotic supplementation for PKU can serve two purposesit can be used to escape behavioral problems associated with treated PKU and it can be utilized to lower absorption of Phe from the gut by utilizing microbial metabolism. Although it has been shown that colonization is not necessary for probiotic action, interactions with the commensal microbiota will make supplementation less controllable and might lead to the unpredictable effects (41). Colonization of a desired probiotic or microbial consortia will therefore lead to longer lasting and more reproducible effects. Thus, for successful probiotic supplementation, general concepts such as community 


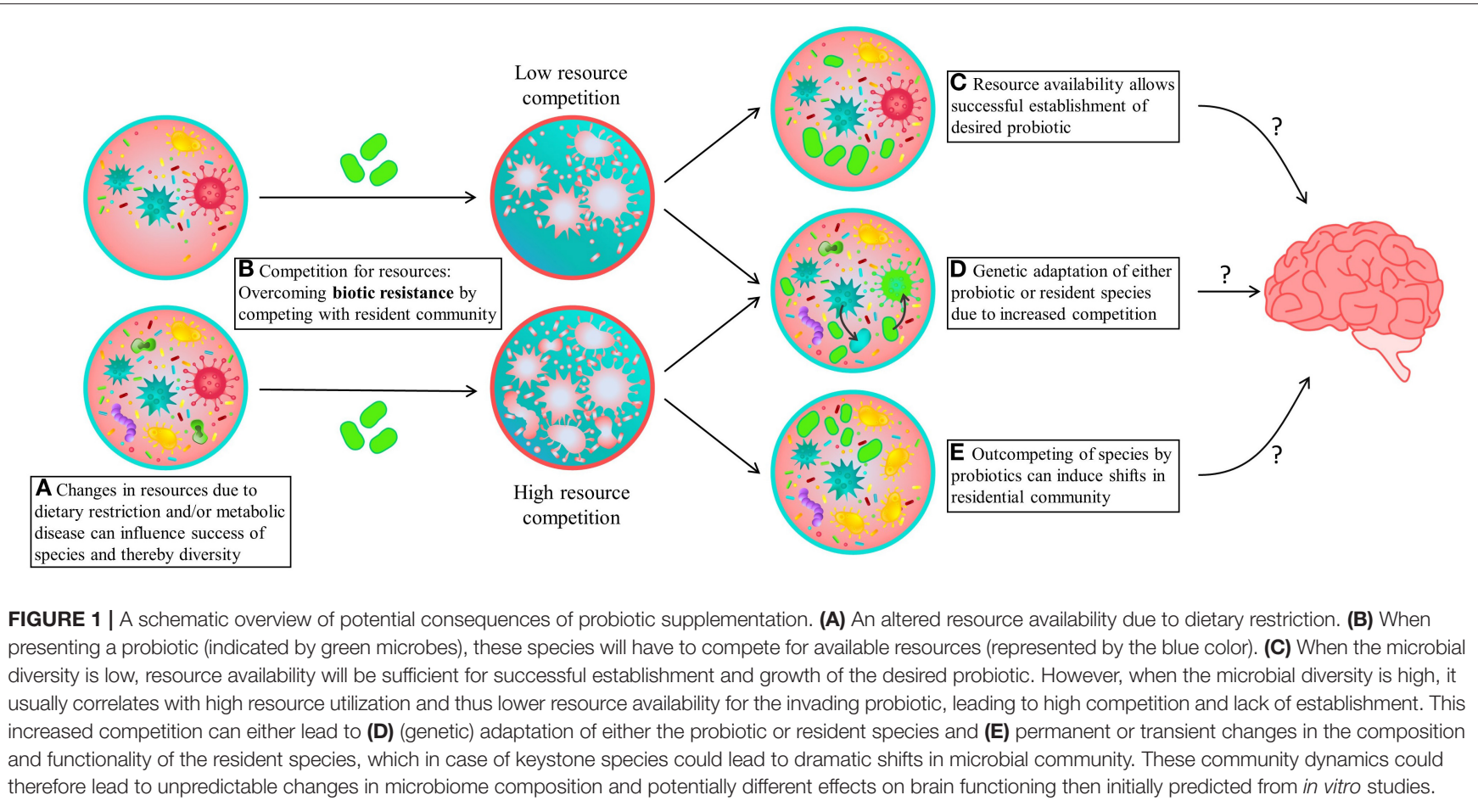

dynamics, microbial invasions and colonization are important to take into consideration to increase treatment effectiveness and safety.

From an ecological perspective, probiotic supplementation can be studied in the context of microbial invasions, where the probiotic non-indigenous strain is introduced in large numbers into an existing community $[(11,42)$; Figure 1]. For microbial invasion to be successful, the invader has to overcome both abiotic (i.e., environmental factors like $\mathrm{pH}$ and temperature) and biotic resistance imposed by the resident community (Figure 1B). Ecological theory predicts that effectiveness and success of a probiotic treatment depends on the ability of the probiotic strain to invade and colonize the gut-which is correlated with their high growth rates, phenotypic plasticity and genetic diversity-but also depends on its capacity to compete for resources in the presence of the native gut microbiome $(11,43,44)$. It has been shown that the success of invasion-in this case, the establishment of a probiotic strain-is negatively correlated with microbiome diversity (11, $45,46)$. Specifically, diverse microbial communities explore the metabolic resources available in the gut in a more efficient manner, thus limiting the number of niches available for invaders (probiotic) to get established. On the other hand, when food resources are not fully consumed and invading species are capable of utilizing empty niches, the chances of establishment and growth are high (Figure 1C). In PKU, dietary restrictions and/or the influence of changes in amino acid profiles are likely responsible for lower species diversity due to altered resource availability, as opposed to liberalized dietary restrictions (Figure 1A). Thus, from the PKU perspective, the observed low gut microbiome diversity might increase the chances of probiotic establishment, although the altered resource availability intrinsic to PKU diet could prevent establishment and survival of the desired probiotics. Additional strategies that increase the probiotic's competitive ability, such as the use of prebiotics that stimulate the growth of the probiotic strain, or high phenotypic plasticity that ensure quick adaptation, might increase the chances of successful colonization therefore improving treatment effectiveness.

Examining microbiome dynamics during colonization (whether is it permanent or not) or whether the microbes were prone to adapt (mutate) within the gut-environment is important to determine safety of a given probiotic (47). In PKU, recent scientific advances give rise to the use of genetically modified probiotics to lower the absorption of Phe from the gut by relying on microbial metabolism (47-50). However, although they have shown to be stable as probiotics, little is known about how these supplements affect the ecological and evolutionary dynamics of commensal microbiota. Even with successful and beneficial introduction of the probiotics, the effects on the resident community, and subsequently behavior, might be more unpredictable - an aspect that is inherent to all microbial invasions $(34,51)$. Moreover, in situations in which the invader needs to compete for available resources, this increases the selective pressures and the propensity for horizontal gene transfer, which could lead to adaptation of either the probiotic or resident species (Figure 1D) (52-55). In the context of genetically modified bacteria, as for instance the Phe lowering probiotic, this could lead to integration of the modification in other (commensal) species, risking unfavorable 
expression of the given genes. Additionally, recent developments have shown that the probiotic properties of certain probiotic strains might be attributed to genes that induce mutational patterns that increase the risk of developing colorectal cancer (56). Thus, a systematic search for naturally occurring gut microbiome strains capable of degrading Phe might represent a more sustainable solution toward personalized medicine, where the evolutionary principles of the gut microbiome are considered (57).

Lastly, ecological principles associated with community dynamics might influence the outcome of microbiome manipulations due to the intricate relationship among microbial populations and their chemical food web $(34,51)$. Due to these community dynamics and its effect on resource availability, successful invasions can displace or shift resident taxa and alter community function, affecting multiple connections within the network $(25,58,59)$. For instance, loss of a keystone species, one that is responsible for many connections in a chemical network, would make the community prone to collapse or create dramatic shifts in composition and function (Figure 1E). Microbiome alterations due to pre- or probiotics can therefore lead to changes in bacterial (metabolite) profile, resulting in different effects than predicted by in vitro studies, and to large impacts on the functionality of the entire microbiome. This could also explain why microbiota transfer therapy shows promising results, whereas supplementation of pre- and probiotics leads to variable results $(60,61)$. Unraveling the dynamics on composition, functionality and potential interactions within the gut microbiome are thus crucial to developing successful microbial based treatments and predicting its effects on microbiome functioning and cognitive outcome.

\section{REFERENCES}

1. Hooper LV, Gordon JI. Commensal host-bacterial relationships in the gut. Science. (2001) 292:1115-8. doi: 10.1126/science.1058709

2. Ley RE, Peterson DA, Gordon JI. Ecological and evolutionary forces shaping microbial diversity in the human intestine. Cell. (2006) 124:837-48. doi: 10.1016/j.cell.2006.02.017

3. Butler MI, Cryan JF, Dinan TG. Man and the microbiome: a new theory of everything? Annu Rev Clin Psychol. (2019) 15:371-98. doi: 10.1146/annurev-clinpsy-050718-095432

4. Vuong HE, Yano JM, Fung TC, Hsiao EY. The microbiome and host behavior. Annu Rev Neurosci. (2017) 40:21-49. doi: 10.1146/annurev-neuro-072116-031347

5. Oyserman BO, Medema MH, Raaijmakers JM. Road MAPs to engineer host microbiomes. Curr Opin Microbiol. (2018) 43:46-54. doi: 10.1016/j.mib.2017.11.023

6. Bercik P, Denou E, Collins J, Jackson W, Lu J, Jury J, et al. The intestinal microbiota affect central levels of brain-derived neurotropic factor and behavior in mice. Gastroenterology. (2011) 141:599-609.e3. doi: 10.1053/j.gastro.2011.04.052

7. Novotný M, Klimova B, Valis M. Microbiome and cognitive impairment: can any diets influence learning processes in a positive way? Front Aging Neurosci. (2019) 11:170. doi: 10.3389/fnagi.2019.00170

8. Rothschild D, Weissbrod O, Barkan E, Kurilshikov A, Korem T, Zeevi D, et al. Environment dominates over host genetics in shaping human gut microbiota. Nature. (2018) 555:210-5. doi: 10.1038/nature 25973

\section{CONCLUDING REMARKS}

Microbial-based strategies for relieving neurological symptoms in various disorders are currently being studied more extensively. Nevertheless, additional research is needed to gain insight in the evolutionary and ecological microbial community dynamics. These dynamics play a critical role in the stability, composition and functional diversity of our gut microbiota, and thus the safety and success of probiotic treatment. Moreover, these ecological principles might explain the discrepancies found between animal and human studies, where results in the often more complex (human) microbiota are less profound and do not lead to the desired outcomes after microbiome manipulation (62, 63). Examining bacterial metabolite profiles resulting from the microbiome could uncover the exact mechanisms by which the gut microbiome influences the brain and hence many behavioral domains. It then could be used to develop personalized probiotic supplementation for disorders requiring dietary treatment, including PKU.

\section{AUTHOR CONTRIBUTIONS}

EG, JF, and EZ came up with the original concept and wrote the paper. EG had the primary responsibility for the final content. All authors read and approved the final manuscript as submitted and contributed in designing the final concept.

\section{FUNDING}

EG was supported by a scholarship from the Adaptive Life Program of the Groningen Institute for Evolutionary Life Sciences, University of Groningen, The Netherlands.

9. Reddel S, Putignani L, Del Chierico F. The impact of low-FODMAPs, Gluten-free, and ketogenic diets on gut microbiota modulation in pathological conditions. Nutrients. (2019) 11:373. doi: 10.3390/nu110 20373

10. Heintz-Buschart A, Wilmes P. Human gut microbiome: function matters. Trends Microbiol. (2018) 26:563-74. doi: 10.1016/j.tim.2017.11.002

11. Mallon CA, Elsas JD, van, and Salles JF. Microbial invasions: the process, patterns, and mechanisms. Trends Microbiol. (2015) 23:719-29. doi: 10.1016/j.tim.2015.07.013

12. Nemergut DR, Schmidt SK, Fukami T, O’Neill SP, Bilinski TM, Stanish LF, et al. Patterns and processes of microbial community assembly. Microbiol Mol Biol Rev. (2013) 77:342-56. doi: 10.1128/MMBR.00051-12

13. Blau N, Van Spronsen FJ, Levy HL. Phenylketonuria. Lancet. (2010) 376:141727. doi: 10.1016/S0140-6736(10)60961-0

14. Fölling A. Über Ausscheidung von Phenylbrenztraubensäure in den Harn als Stoffwechselanomalie in Verbindung mit Imbezillität. Hoppe-Seyler's Zeitschrift für Physiol Chem. (1934) 227:169-81. doi: 10.1515/bchm2.1934.227.1-4.169

15. van Spronsen FJ, van Wegberg AM, Ahring K, Bélanger-Quintana A, Blau N, Bosch AM, et al. Key European guidelines for the diagnosis and management of patients with phenylketonuria. lancet Diabetes Endocrinol. (2017) 5:743-56. doi: 10.1016/S2213-8587(16)30320-5

16. Bickel H, Gerrard J, Hickmans EM, Bickel $H$. Influence of phenylalanine intake on phenylketonuria. Lancet. (1953) 265:812-3. doi: 10.1016/S0140-6736(53)90473-5

17. Woolf LI, Griffiths R, Moncrieff A. Treatment of phenylketonuria with a diet low in phenylalanine. Br MedJ. (1955) 1:57-64. doi: 10.1136/bmj.1.4905.57 
18. Weglage J, Möller HE, Wiedermann D, Cipcic-Schmidt S, Zschocke J, Ullrich K. In vivo NMR spectroscopy in patients with phenylketonuria: clinical significance of interindividual differences in brain phenylalanine concentrations. J Inherit Metab Dis. (1998) 21:81-2. doi: $10.1023 / \mathrm{A}: 1005327801588$

19. Burlina AP, Lachmann RH, Manara R, Cazzorla C, Celato A, van Spronsen FJ, et al. The neurological and psychological phenotype of adult patients with early-treated phenylketonuria: a systematic review. J Inherit Metab Dis. (2019) 42:209-19. doi: 10.1002/jimd.12065

20. Enns GM, Koch R, Brumm V, Blakely E, Suter R, Jurecki E. Suboptimal outcomes in patients with PKU treated early with diet alone: revisiting the evidence. Mol Genet Metab. (2010) 101:99-109. doi: 10.1016/j.ymgme.2010.05.017

21. Jahja R, van Spronsen FJ, de Sonneville LMJ, van der Meere JJ, Bosch AM, Hollak CEM, et al. Social-cognitive functioning and social skills in patients with early treated phenylketonuria: a PKU-COBESO study. J Inherit Metab Dis. (2016) 39:355-62. doi: 10.1007/s10545-016-9918-0

22. Manti F, Nardecchia F, Paci S, Chiarotti F, Carducci C, Carducci C, et al. Predictability and inconsistencies in the cognitive outcome of early treated PKU patients. J Inherit Metab Dis. (2017) 40:793-9. doi: 10.1007/s10545-017-0082-y

23. Bourget L, Chang TMS. Effects of oral administration of artificial cells immobilized phenylalanine ammonia-lyase on intestinal amino acids of phenylketonuric rats. Biomater Artif Cells Artif Organs. (1989) 17:161-81. doi: 10.3109/10731198909118278

24. Duan K, Sibley CD, Davidson CJ, Surette MG. Chemical interactions between organisms in microbial communities. In: Bacterial Sensing and Signaling (Basel: KARGER), (2009). p. 1-17. doi: 10.1159/000219369

25. Niehaus L, Boland I, Liu M, Chen K, Fu D, Henckel C, et al. Microbial coexistence through chemical-mediated interactions. Nat Commun. (2019) 10:2052. doi: 10.1038/s41467-019-10062-x

26. Czárán TL, Hoekstra RF, Pagie L. Chemical warfare between microbes promotes biodiversity. Proc Natl Acad Sci USA. (2002) 99:786-90. doi: 10.1073/pnas.012399899

27. Dethlefsen L, Eckburg PB, Bik EM, Relman DA. Assembly of the human intestinal microbiota. Trends Ecol Evol. (2006) 21:517-23.

28. Bassanini G, Ceccarani C, Borgo F, Severgnini M, Rovelli V, Morace G, et al. Phenylketonuria diet promotes shifts in firmicutes populations. Front Cell Infect Microbiol. (2019) 9:101. doi: 10.3389/fcimb.2019.00101

29. De Oliveira FP, Mendes RH, Dobbler PT, Mai V, Pylro VS, Waugh SG, et al. Phenylketonuria and gut microbiota: a controlled study based on next-generation sequencing. PLoS ONE. (2016) 11:1-15. doi: 10.1371/journal.pone. 0157513

30. Sawin EA, De Wolfe TJ, Aktas B, Stroup BM, Murali SG, Steele JL, et al. Glycomacropeptide is a prebiotic that reduces Desulfovibrio bacteria, increases cecal short-chain fatty acids, and is anti-inflammatory in mice. Am J Physiol - Gastrointest Liver Physiol. (2015) 309 G590-601. doi: 10.1152 /ajpgi.00211.2015

31. Verduci E, Moretti F, Bassanini G, Banderali G, Rovelli V, Casiraghi MC, et al. Phenylketonuric diet negatively impacts on butyrate production. Nutr Metab Cardiovasc Dis. (2018) 28:385-92. doi: 10.1016/j.numecd.2018.01.004

32. MacDonald A, Cochrane B, Wopereis H, Loveridge N. Specific prebiotics in a formula for infants with Phenylketonuria. Mol Genet Metab. (2011) 104:S55-S59. doi: 10.1016/j.ymgme.2011.09.015

33. Mallon CA, Poly F, Le Roux X, Marring I, van Elsas JD, Salles JF. Resource pulses can alleviate the biodiversity-invasion relationship in soil microbial communities. Ecology. (2015) 96:915-26. doi: 10.1890/14-1001.1

34. Mallon CA, Le Roux X, Van Doorn GS, Dini-Andreote F, Poly F, Salles JF. The impact of failure: unsuccessful bacterial invasions steer the soil microbial community away from the invader's niche. ISME J. (2018) 12:72841. doi: 10.1038/s41396-017-0003-y

35. Colonetti K, Roesch LF, Schwartz IVD. The microbiome and inborn errors of metabolism: why we should look carefully at their interplay? Genet Mol Biol. (2018) 41:515-32. doi: 10.1590/1678-4685-gmb-2017-0235

36. Ney DM, Murali SG, Stroup BM, Nair N, Sawin EA, Rohr F, et al. Metabolomic changes demonstrate reduced bioavailability of tyrosine and altered metabolism of tryptophan via the kynurenine pathway with ingestion of medical foods in phenylketonuria. Mol Genet Metab. (2017) 121:96-103. doi: 10.1016/j.ymgme.2017.04.003

37. Stroup BM, Nair N, Murali SG, Broniowska K, Rohr F, Levy HL, et al. Metabolomic markers of essential fatty acids, carnitine, and cholesterol metabolism in adults and adolescents with phenylketonuria. J Nutr. (2018) 148:194-201. doi: 10.1093/jn/nxx039

38. Wild J, Shanmuganathan M, Hayashi M, Potter M, Britz-Mckibbin P. Metabolomics for improved treatment monitoring of phenylketonuria: urinary biomarkers for non-invasive assessment of dietary adherence and nutritional deficiencies. Analyst. (2019) 144:6595-608. doi: 10.1039/C9AN01642B

39. Karlsson FH, Tremaroli V, Nookaew I, Bergström G, Behre CJ, Fagerberg B, et al. Gut metagenome in European women with normal, impaired and diabetic glucose control. Nature. (2013) 498:99-103. doi: 10.1038/nature 12198

40. Zhao L, Zhang F, Ding X, Wu G, Lam YY, Wang X, et al. Gut bacteria selectively promoted by dietary fibers alleviate type 2 diabetes. Science. (2018) 359:1151-6. doi: 10.1126/science.aao5774

41. Wieërs G, Belkhir L, Enaud R, Leclercq S, Philippart de Foy JM, Dequenne I, et al. How probiotics affect the microbiota. Front Cell Infect Microbiol. (2020) 9:454. doi: $10.3389 /$ fcimb.2019.00454

42. Adam E, Groenenboom AE, Kurm V, Rajewska M, Schmidt R, Tyc O, et al. Controlling the microbiome: microhabitat adjustments for successful biocontrol strategies in soil and human gut. Front Microbiol. (2016) 7:1079. doi: 10.3389/fmicb.2016.01079

43. Keddy PA. Assembly and response rules: two goals for predictive community ecology. J Veg Sci. (1992) 3:157-64. doi: 10.2307/3235676

44. Theoharides KA, Dukes JS. Plant invasion across space and time: factors affecting nonindigenous species success during four stages of invasion. New Phytol. (2007) 176:256-73. doi: 10.1111/j.1469-8137.2007.02207.x

45. Eisenhauer N, Schulz W, Scheu S, Jousset A. Niche dimensionality links biodiversity and invasibility of microbial communities. Funct Ecol. (2013) 27:282-8. doi: $10.1111 / j .1365-2435.2012 .02060 . x$

46. Jousset A, Schulz W, Scheu S, Eisenhauer N. Intraspecific genotypic richness and relatedness predict the invasibility of microbial communities. ISME J. (2011) 5:1108-14. doi: 10.1038/ismej.2011.9

47. Crook N, Ferreiro A, Gasparrini AJ, Pesesky MW, Gibson MK, Wang B, et al. Adaptive strategies of the candidate probiotic E. coli nissle in the mammalian. Gut Cell Host Microbe. (2019) 25:499-512.e8. doi: 10.1016/j.chom.2019.02.005

48. Durrer KE, Allen MS, Hunt von Herbing I. Genetically engineered probiotic for the treatment of phenylketonuria (PKU); assessment of a novel treatment in vitro in the PAHenu2 mouse model of PKU. PLoS ONE(2017) 12:e0176286. doi: 10.1371/journal.pone.0176286

49. Isabella VM, Ha BN, Castillo MJ, Lubkowicz DJ, Rowe SE, Millet YA, et al. Development of a synthetic live bacterial therapeutic for the human metabolic disease phenylketonuria. Nat Biotechnol. (2018) 36:857-64. doi: $10.1038 /$ nbt. 4222

50. Ramírez AM, Rodriguez-López A, Ardila A, Beltran L, Patarroyo CA, Melendez ADP, et al. Production of human recombinant phenylalanine hydroxylase in Lactobacillus plantarum for gastrointestinal delivery. Eur $J$ Pharm Sci. (2017) 109:48-55. doi: 10.1016/j.ejps.2017.07.033

51. Mawarda PC, Le Roux X, Dirk van Elsas J, Salles JF. Deliberate introduction of invisible invaders: a critical appraisal of the impact of microbial inoculants on soil microbial communities. Soil Biol Biochem. (2020) 148:107874. doi: 10.1016/j.soilbio.2020.107874

52. Hehemann JH, Correc G, Barbeyron T, Helbert W, Czjzek M, Michel G. Transfer of carbohydrate-active enzymes from marine bacteria to Japanese gut microbiota. Nature. (2010) 464:908-12. doi: 10.1038/nature08937

53. Liu L, Chen X, Skogerb,ø G, Zhang P, Chen R, He S, et al. The human microbiome: a hot spot of microbial horizontal gene transfer. Genomics(2012) 100:265-70. doi: 10.1016/j.ygeno.2012.07.012

54. Sitaraman R. Prokaryotic horizontal gene transfer within the human holobiont: ecological-evolutionary inferences, implications and possibilities. Microbiome. (2018) 6:163. doi: 10.1186/s40168-018-0551-z

55. Whitney KD, Gabler CA. Rapid evolution in introduced species, 'invasive traits' and recipient communities: challenges for predicting invasive potential. Divers Distrib. (2008) 14:569-80. doi: 10.1111/j.1472-4642.2008.00473.x 
56. Pleguezuelos-Manzano C, Puschhof J, Rosendahl Huber A, van Hoeck A, Wood HM, Nomburg J, et al. Mutational signature in colorectal cancer caused by genotoxic pks+ E. coli. Christopher Garcia. (2020) 580:18. doi: 10.1038/s41586-020-2080-8

57. Ma N, Ma X. Dietary amino acids and the gut-microbiome-immune axis: physiological metabolism and therapeutic prospects. Compr Rev Food Sci Food Saf. (2019) 18:221-42. doi: 10.1111/1541-4337.12401

58. Amor DR, Ratzke C, Gore J. Transient invaders can induce shifts between alternative stable states of microbial communities. Sci Adv. (2020) 6:eaay8676. doi: 10.1126/sciadv.aay8676

59. Sanders ME. Impact of probiotics on colonizing microbiota of the gut. J Clin Gastroenterol. (2011) 45:S115-S119. doi: 10.1097/MCG.0b013e318227414a

60. Tsai YL, Lin TL, Chang CJ, Wu TR, Lai WF, Lu CC, et al. Probiotics, prebiotics and amelioration of diseases. J Biomed Sci. (2019) 26:3. doi: 10.1186/s12929-018-0493-6

61. Zeng W, Shen J, Bo T, Peng L, Xu H, Ide Nasser M, et al. Cutting edge: probiotics and fecal microbiota transplantation in immunomodulation. $J$ Immunol Res. (2019) 2019:1603758. doi: 10.1155/2019/1603758
62. Abid MB, Koh CJ. Probiotics in health and disease: fooling Mother Nature? Infection. (2019) 47:911-7. doi: 10.1007/s15010-01901351-0

63. Durack J, Lynch SV. The gut microbiome: relationships with disease and opportunities for therapy. J Exp Med. (2018) 216:20-40. doi: $10.1084 /$ jem.20180448

Conflict of Interest: The authors declare that the research was conducted in the absence of any commercial or financial relationships that could be construed as a potential conflict of interest.

Copyright (C) 2020 van der Goot, van Spronsen, Falcão Salles and van der Zee. This is an open-access article distributed under the terms of the Creative Commons Attribution License (CC BY). The use, distribution or reproduction in other forums is permitted, provided the original author(s) and the copyright owner(s) are credited and that the original publication in this journal is cited, in accordance with accepted academic practice. No use, distribution or reproduction is permitted which does not comply with these terms. 